\title{
Transferência de imunidade passiva em bezerros das raças Nelore e Limousin e proteinograma sérico nos primeiros quatro meses de vida ${ }^{1}$
}

\author{
Márcio Carvalho da Costa ${ }^{2}$, Karina Keller Marques da Costa Flaiban², Mariana \\ Marcantonio Coneglian ${ }^{3}$, Francisco Leydson Formiga Feitosa ${ }^{4}$, Mara Regina \\ Stipp Balarin ${ }^{5}$ e Júlio Augusto Naylor Lisbôa6*
}

\begin{abstract}
Costa M.C., Flaiban K.K.M.C., Coneglian M.M., Feitosa F.L.F., Balarin M.R.S. \& Lisbôa J.A.N. 2008. [Passive transfer of immunity in Nelore and Limousin calves and serum proteinogram in the first four months of life.] Transferência de imunidade passiva em bezerros das raças Nelore e Limousin e proteinograma sérico nos primeiros quatro meses de vida. Pesquisa Veterinária Brasileira 28(9):410-416. Departamento de Clínicas Veterinárias, Centro de Ciências Agrárias, Universidade Estadual de Londrina, Campus Universitário, Cx. Postal 6001, Londrina, PR 86051-990, Brazil. E-mail: janlisboa@uel.br

To study the passive transfer of immunity, 90 healthy calves, 45 Nelore and 45 Limousin, were grouped ( $n=15)$ according to their dam's parity: first, second or third or more calvings. Blood samples were draw from each calf with 24 to 36 hours of life and 15, 30, 60, 90, and 120 days. The total serum (TSP) and plasma (TPP) proteins, gamaglutamiltransferase activity (GGT), serum albumin, alpha, beta and gammaglobulin by electrophoresis in agarose gel and IgG estimated by the zinc sulphate turbidity test were determined. Two-way-ANOVA was used to compare the data in the first age. The age behaviour was analysed through repeated measures ANOVA. Correlations were established between the variables. The passive transfer of immunity was successful in both breeds and the parity of the dam had no effect on the calves' serum gammaglobulin concentration. The levels of gammaglobulins were higher at the end of the first day of life, and decreased until 60 days. From there on, the increase due to the active production of antibodies was precocious in taurine calves and slower in Zebu calves. At the end of the first day of life, the gammaglobulin was correlated with IgG $(r=0,859)$, TPP $(r=0,807)$, TSP $(r=0,811)$ and GGT $(r=0,399)$. The variation of serum proteins followed the normal pattern throughout the first four months of life, with little differences between taurine and Zebu calves.
\end{abstract}

INDEX TERMS: Calves, Zebu, taurine, serum proteins, immunoglobulins.

\footnotetext{
1 Recebido em 25 de março de 2008.

Aceito para publicação em 13 de setembro de 2008.

Dissertação de Mestrado do primeiro autor; apoio financeiro da CAPES, da Fundação Araucária (Proc. n 4662; Edital 05/2003) e da FAEPE/PROPPG/UEL.

2 Discente do Programa de Pós-graduação em Ciência Animal, Universidade Estadual de Londrina (UEL).

${ }^{3}$ Acadêmico de Medicina Veterinária da UEL. Bolsista de Iniciação Científica.

${ }^{4}$ Departamento de Clínica, Cirurgia e Reprodução Animal, FOA, Unesp, Campus de Araçatuba, Cx. Postal 261, Araçatuba, SP 16050680, Brasil.

${ }^{5}$ Departamento de Medicina Veterinária Preventiva, Centro de Ciências Agrárias (CCA), UEL, Londrina, PR, Brasil.

${ }^{6}$ Departamento de Clínicas Veterinárias, CCA, UEL, Campus Universitário, Cx. Postal 6001, Londrina, PR 86051-990. *Autor para correspondência:janlisboa@uel.br
}

RESUMO.- Com o objetivo de investigar alguns aspectos relacionados à transferência de imunidade passiva em bovinos de corte, foram selecionados 90 bezerros aparentemente sadios, 45 da raça Nelore e 45 da raça Limousin, distribuídos em 3 grupos (com 15 bezerros cada) de acordo com o número de parições de suas mães: primeira cria; segunda cria; e terceira ou mais crias. Amostras de sangue foram colhidas de cada bezerro entre 24 e 36 horas de vida e com 15, 30, 60, 90 e 120 dias. Determinaram-se as concentrações de proteína total no soro (PT) e no plasma (PPT), a atividade sérica da gamaglutamiltransferase (GGT), e as concentrações séricas de albumina, alfa, beta e gamaglobulinas por eletroforese em gel de agarose e de IgG estimada por meio do método de turvação pelo sulfato de zinco. Empregou-se a análise de variância bifatorial para 
as variáveis mensuradas na primeira colheita. O comportamento das variáveis em função da idade foi estudado por meio da análise de variância de medidas repetidas. Correlações foram estabelecidas entre as variáveis. A transferência de imunidade passiva foi bem sucedida nos bezerros de ambas as raças e o número de parições das mães não interferiu no processo. As concentrações mais elevadas de gamaglobulinas ao término do primeiro dia de vida declinaram até valores mínimos aos 60 dias. A partir dessa idade, a elevação conseqüente à produção ativa de anticorpos foi mais precoce nos bezerros taurinos e mais lenta nos zebuínos. A gamaglobulina, ao término do primeiro dia de vida, correlacionou-se com as seguintes variáveis: IgG $(r=0,859)$, PPT $(r=0,807)$, PT $(r=0,811)$ e GGT $(r=0,399)$. $O$ fator etário exerceu efeito sobre todas as variáveis mensuradas. As variações das proteínas séricas obedeceram a um padrão de comportamento fisiológico ao longo dos quatro primeiros meses de vida, de forma geral, não distinto em taurinos e zebuínos.

TERMOS DE INDEXAÇÃO: Bezerros, zebuínos, taurinos, proteínas séricas, imunoglobulinas.

\section{INTRODUÇÃO}

A mortalidade de bezerros nos primeiros meses de vida é uma das principais causas de prejuízo para a bovinocultura mundial, sendo a falha na transferência de imunidade passiva (FTIP) um fator de grande contribuição para essas mortes (Selim et al. 1995, Wittum \& Perino 1995). Na espécie bovina, a placenta do tipo sindesmocorial impede a transferência de imunoglobulinas (Ig) da mãe para o feto (Tizard 2002). Os bezerros são obrigados a adquirir esses anticorpos após o nascimento por meio da ingestão do colostro materno rico nessas proteínas (Besser \& Gay 1994, Fagliari et al. 1996, Borges 1997, Feitosa et al. 2001a, Bessi et al. 2002).

Sabe-se que vacas leiteiras mais jovens produzem colostro com concentrações menores de Ig quando comparadas a animais com maior número de parições (Muller \& Ellinger 1981, Besser \& Gay 1994, Feitosa et al. 1999). Fêmeas de raças de corte apresentam colostro com maior concentração de Ig (Guy et al. 1994), sendo incomum a influência do número de parições sobre a transferência de anticorpos maternos (Perino et al. 1995, Filteau et al. 2003). No entanto, produtos de novilhas estão mais sujeitos a fatores de risco que podem levar a uma menor absorção intestinal de anticorpos (Radostits \& Acres 1980, Norman \& Hohenboken 1981, Petrie et al. 1984, Machado Neto et al. 1997).

No Brasil, a transferência de imunidade passiva (TIP) já está bem caracterizada nos bovinos leiteiros (Ribeiro et al. 1983, Fagliari et al. 1996, 1998, Borges 1997, Moraes et al. 1997, Costa 2000, Feitosa et al. 2001b, Pauletti et al. 2002, Leal et al. 2003). Porém, existe um menor número de estudos nas raças de corte, e principalmente nos zebuínos (Machado Neto \& D’Arce 1979, Fagliari et al. 1988, 1998, Amorim 2002, Machado Neto et al. 2004).
Este estudo foi realizado com o objetivo de avaliar aspectos relacionados à transferência de imunidade passiva em bezerros de corte das raças Nelore e Limousin manejados extensivamente sob condições naturais, e de investigar o comportamento das proteínas séricas ao longo dos primeiros quatro meses de vida.

\section{MATERIAL E MÉTODOS}

O projeto foi executado por uma equipe multidisciplinar envolvendo o Ambulatório de Clínica Médica de Grandes Animais e o Laboratório de Patologia Clínica do Hospital Veterinário da Universidade Estadual de Londrina. O protocolo foi aprovado pelo Comitê de Ética em Experimentação Animal da UEL (CEEA/ UEL) sob o número de registro 14/05.

Foram selecionados, aleatoriamente, 90 bezerros produtos de partos eutócicos, aparentemente sadios ao nascimento e ao longo do primeiro dia de vida, sendo 45 da raça Nelore e 45 da raça Limousin. Os bezerros de cada raça foram distribuídos em três grupos de acordo com o número de parições das mães: primeira cria, segunda cria e terceira ou mais crias, perfazendo o total de seis grupos com 15 animais cada. Ambas as propriedades, localizadas na região norte do Paraná, praticavam manejo extensivo convencional sob condições naturais com controle individual do plantel e bom padrão de manejos nutricional e sanitário. Durante todo o período experimental a observação dos animais era realizada duas vezes ao dia, ocasiões em que se identificava a ocorrência dos nascimentos, a vitalidade dos bezerros recém-nascidos e a manifestação de doenças ou outras alterações. Os bezerros permaneceram constantemente em contato com as suas mães desde o nascimento e não receberam qualquer auxílio para a mamada do colostro. O curativo do umbigo era realizado uma única vez, no primeiro dia de vida com produto à base de iodofórmio, fenol, ácido pícrico e diclorvós (Umbicura). A tatuagem (raça Limousin) ou a aplicação de brinco (raça Nelore) para identificação individual era realizada logo após o curativo do umbigo. Ao longo dos primeiros quatro meses de vida nenhum bezerro foi vacinado ou submetido a qualquer tipo de modificação no manejo.

As amostras de sangue foram obtidas por venopunção da jugular com uso de agulhas $25 \times 0,7 \mathrm{~mm}$ (PrecisionGlide, BD) para colheita em frasco a vácuo de $10 \mathrm{~mL}$ sem anticoagulante (Vacoum II, Labnew) e em frasco a vácuo de $5 \mathrm{~mL}$ com anticoagulante EDTA 15\% (Vacoum II, Labnew). As colheitas foram realizadas seqüencialmente nas seguintes idades: 24 a 36 horas de vida, 15, 30, 60, 90 e 120 dias. O soro foi obtido por centrifugação após a retração do coágulo e conservado por congelação a $20^{\circ} \mathrm{C}$ negativos até o momento das análises.

As concentrações plasmáticas de proteínas totais e de fibrinogênio, após a coagulação pelo calor, foram determinadas por refratometria (refratômetro Attago) obedecendo-se o método tradicional (Schalm et al. 1975). A concentração de proteínas séricas foi obtida pelo método do biureto (Gornal et al. 1949) utilizando-se reagentes comerciais (Biotécnica) e leitura espectrofotométrica (Airone 200, Wienerlab). A atividade da gamaglutamiltransferase foi determinada pelo método cinético colorimétrico segundo a técnica modificada de Szasz et al. (1969), empregando-se reagentes comerciais (Gold Analisa) e leitura espectrofotométrica (Airone 200, Wienerlab).

As concentrações séricas das frações protéicas albumina, alfa $_{1}$, alfa $a_{2}$, beta e gamaglobulinas foram determinadas por eletroforese (Kremers et al. 1967). Empregou-se gel de agarose 
(Celmgel, CELM), tampão Tris de pH 9,5 (CELM) e corrida eletroforética por $20 \mathrm{~min}$ em corrente de 100V (Sistema SE250, CELM). Após o procedimento, o gel foi corado com negro de amido $2 \%$ e descorado com ácido acético $5 \%$. A proporção de cada fração protéica foi estabelecida por meio do programa de informática SDS-60 do sistema SE-250 (CELM) após leitura realizada em scanner.

A concentração sérica de imunoglobulinas $G$ foi estimada pela técnica de turvação pelo sulfato de zinco com leitura espectrofotométrica, conforme o método empregado por Pfeifer et al. (1977) com modificações. Adicionou-se $0,1 \mathrm{~mL}$ de soro a $6 \mathrm{~mL}$ de uma solução contendo $208 \mathrm{mg}$ de $\mathrm{ZnSO}_{4} \cdot 7 \mathrm{H}_{2} \mathrm{O}$ por litro de água destilada. Após uma hora de repouso, a absorbância da mistura foi mensurada por espectrofotometria (Cintra 5, GBC Scientific Equipment) em comprimento de onda de $620 \mathrm{~nm}$. Devido à instabilidade da solução, foram realizadas três leituras e considerada a média final. A quantidade de IgG foi estimada com o uso de uma curva padrão previamente traçada com concentrações conhecidas de IgG bovina (Single Radial Immunodiffusion Kit; VRMD, EUA), a saber: zero (soro fetal bovino), $400,800,1600$ e $3200 \mathrm{mg} / \mathrm{dL}$. As amostras que superaram o valor estimado de $3200 \mathrm{mg} / \mathrm{dL}$ foram processadas novamente após diluição do soro em solução fisiológica na proporção de $1: 1$.

Para avaliar os efeitos da raça, do número de parições das mães e da interação entre os dois fatores sobre as variáveis mensuradas na primeira colheita, foi empregada a análise de variância bifatorial. O comportamento das variáveis com o avançar da idade e de acordo com a raça foi avaliado por análise de variâncias de medidas repetidas bifatorial. O teste de Tukey foi empregado para a comparação entre médias, admitindo-se uma probabilidade de erro de $5 \%$. Foram estabelecidos os coeficientes de correlação entre as variáveis estudadas (Curi 1998).

\section{RESULTADOS E DISCUSSÃO}

O número de parição das vacas não determinou efeito sobre a concentração sérica de gamaglobulinas nos bezerros ao término do primeiro dia de vida (Fig.1). O mesmo se verificou para os valores médios de proteínas plasmáticas totais (PPT), proteínas totais no soro (PT), imunoglobulina G estimada (IgG), globulinas (Glob) e da atividade sérica da gamaglutamiltransferase (GGT). Em conjunto, esses resultados indicam que o número de partos das mães não interferiu com o processo de TIP. Considerando evidências anteriores em bezerros de corte, existe coerência com as observações de Petrie et al. (1984), de Perino et al. (1995) e de Filteau et al. (2003). Por outro lado, Bradley et al. (1979), Norman e Hohenboken (1981) e Machado Neto et al. (1997) constataram concentrações séricas de imunoglobulinas menores em produtos de primíparas o que, no entanto, não caracterizou FTIP.

Em várias oportunidades se comprovou que a concentração de IgG no colostro tende a aumentar conforme o número de parições nas fêmeas de raças leiteiras (Oyeniyi \& Hunter 1978, Muller \& Ellinger 1981, Devery-Pocius \& Larson 1983, Pritchett et al. 1991, Feitosa et al. 1999) e de corte (Norman \& Hohenboken 1981), o que sugere que produtos de primíparas poderiam ser mais propensos à

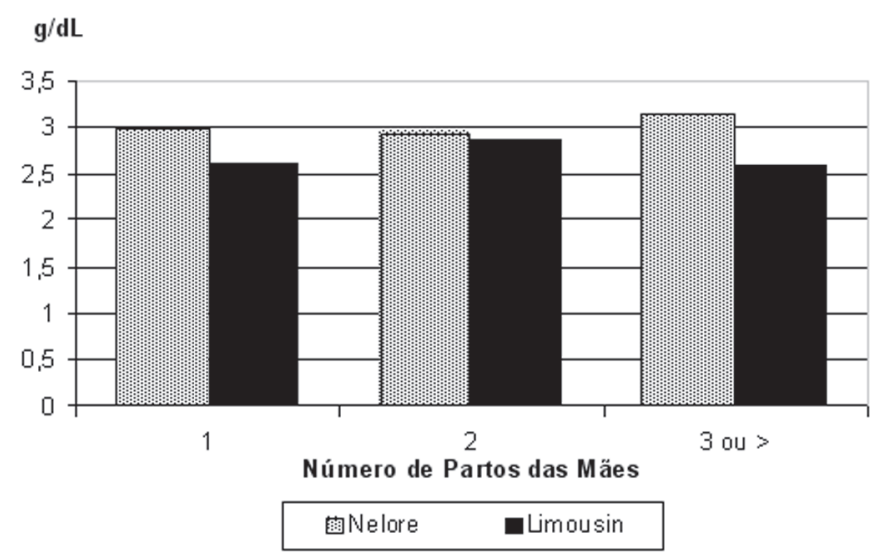

Fig.1. Concentração sérica de gamaglobulinas em bezerros das raças Nelore e Limousin, 24 a 36 horas após o nascimento, agrupados de acordo com o número de parições das mães.

FTIP (Feitosa et al. 1999). Essa chance é provavelmente menor nas raças de corte uma vez que a concentração de IgG é geralmente maior no colostro em comparação às fêmeas leiteiras (Besser \& Gay 1994, Guy et al. 1994). Essas últimas produzem maior volume, o que pode provocar maior diluição (Prichett et al. 1991, Guy et al. 1994).

Vacas de primeira cria de raças de corte podem, eventualmente, produzir volumes de colostro insuficientes para a proteção de seus bezerros, assim como, podem ser mais propensas a rejeitá-los (Radostits \& Acres 1980, Petrie et al. 1984). Tais condições não se confirmaram no presente trabalho e a TIP foi bem sucedida em ambas as raças estudadas.

As biotécnicas da reprodução são empregadas, na atualidade, em escala cada vez maior nos rebanhos de corte brasileiros de maior valor genético e comercial. As fêmeas bovinas nulíparas são usualmente a opção preferida para exercerem o papel de receptoras de embrião. Entende-se que o sucesso da gestação seja maior porque a probabilidade de infecção uterina é muito reduzida. Pode-se pressupor, a partir dos resultados obtidos, que a utilização de novilhas seja segura também quanto ao aspecto da proteção imunitária do recém-nascido.

A concentração sérica de gamaglobulinas observada ao término do primeiro dia de vida não diferiu entre taurinos e zebuínos (Fig.1). Ao contrário, os bezerros Nelore exibiram médias ligeiramente superiores de PPT, PT, IgG, GGT $(p<0,01)$ e globulinas $(p<0,05)$ nessa primeira idade (Quadros 1 e 2). Fagliari et al. (1998) também relataram valores de PT e globulinas mais altos em bezerros Nelore comparados a Holandeses, porém as médias de GGT não diferiram. Machado Neto et al. (2004), por outro lado, verificaram valores mais elevados de PT nos bezerros Canchim do que nos da raça Nelore, e a concentração de IgG não foi diferente. As diferenças entre as médias, ainda que significativas, são de pequena magnitude e não caracterizam uma superioridade dos zebuínos sobre os taurinos. De fato, pode-se considerar que o processo de TIP tenha sido bem sucedido nas duas raças. 
Quadro 1 Valores médios e desvios-padrão $(x \pm s)$ de proteínas séricas totais $(\mathrm{PT})$, proteínas plasmáticas totais (PPT), fibrinogênio (Fib), albumina (Alb), alfa , $_{\text {alfa }}$, beta e gamaglobulinas, globulina total (Glob), relação albumina:globulina $(A: G)$, imunoglobulina $\mathrm{G}(\mathrm{IgG})$ e atividade da gamaglutamiltransferase (GGT) em bezerros sadios da raça Nelore nos primeiros 120 dias de vida

\begin{tabular}{|c|c|c|c|c|c|c|}
\hline & 24 a $36 \mathrm{~h}$ & 15 dias & 30 dias & 60 dias & 90 dias & 120 dias \\
\hline PT (g/dL) & $7,19 \pm 0,75^{a}$ & $6,51 \pm 0,46^{b}$ & $6,15 \pm 0,42^{c}$ & $5,98 \pm 0,39^{c}$ & $5,94 \pm 0,37^{c}$ & $6,11 \pm 0,38^{\mathrm{C}}$ \\
\hline PPT (g/dL) & $9,06 \pm 0,77^{a}$ & $8,02 \pm 0,43^{b}$ & $7,74 \pm 0,39^{c}$ & $7,56 \pm 0,36^{d}$ & $7,47 \pm 0,35^{d}$ & $7,84 \pm 0,44^{b c}$ \\
\hline Fib (mg/dL) & $374 \pm 151^{\text {ab }}$ & $404 \pm 172 a b$ & $417 \pm 183^{a}$ & $389 \pm 135^{a b}$ & $322 \pm 123^{b}$ & $450 \pm 189^{a}$ \\
\hline Alb (g/dL) & $2,44 \pm 0,35^{d}$ & $3,17 \pm 0,23^{c}$ & $3,50 \pm 0,26^{b}$ & $3,59 \pm 0,36^{a b}$ & $3,73 \pm 0,26^{a}$ & $3,60 \pm 0,31^{a b}$ \\
\hline Alfa $_{1}$ (g/dL) & $0,41 \pm 0.09^{a}$ & $0,42 \pm 0.07^{a}$ & $0,42 \pm 0.06^{a}$ & $0,43 \pm 0.09^{a}$ & $0,32 \pm 0.06^{b}$ & $0,29 \pm 0.06^{b}$ \\
\hline $\mathrm{Alfa}_{2}(\mathrm{~g} / \mathrm{dL})$ & $0,37 \pm 0.06^{d}$ & $0,44 \pm 0.09^{c}$ & $0,44 \pm 0.07^{c}$ & $0,53 \pm 0.09^{b}$ & $0,51 \pm 0.06^{b}$ & $0,61 \pm 0 \cdot 10^{\mathrm{a}}$ \\
\hline Beta (g/dL) & $0,95 \pm 0,18^{a}$ & $0,97 \pm 0,13^{a}$ & $0,86 \pm 0,11^{b}$ & $0,72 \pm 0,08^{c}$ & $0,63 \pm 0,10^{d}$ & $0,62 \pm 0,09^{d}$ \\
\hline Gama (g/dL) & $3,04 \pm 0,75^{a}$ & $1,51 \pm 0,37^{b}$ & $0,93 \pm 0,19^{c}$ & $0,69 \pm 0,18^{d}$ & $0,74 \pm 0,22^{\mathrm{cd}}$ & $0,97 \pm 0,28^{\mathrm{c}}$ \\
\hline Glob (g/dL) & $4,76 \pm 0,78^{a}$ & $3,35 \pm 0,42^{b}$ & $2,65 \pm 0,30^{c}$ & $2,39 \pm 0,28^{\mathrm{de}}$ & $2,20 \pm 0,34^{\mathrm{e}}$ & $2,50 \pm 0,39^{\mathrm{cd}}$ \\
\hline$A: G$ & $0,53 \pm 0,13^{e}$ & $0,96 \pm 0,15^{d}$ & $1,34 \pm 0,17^{c}$ & $1,53 \pm 0,25^{b}$ & $1,73 \pm 0,28^{a}$ & $1,48 \pm 0,31^{b}$ \\
\hline $\lg G(g / d L)$ & $3,75 \pm 0,63^{a}$ & $3,06 \pm 0,47^{b}$ & $2,57 \pm 0,28^{c}$ & $2,22 \pm 0,28^{\text {de }}$ & $2,18 \pm 0,34^{e}$ & $2,45 \pm 0,50^{\mathrm{cd}}$ \\
\hline GGT UI/L & $1700.0 \pm 940,13^{a}$ & $173.90 \pm 100,17^{b}$ & $41,56 \pm 21,90^{b}$ & $16,91 \pm 4,89^{b}$ & $16,77 \pm 6,33^{b}$ & $14,04 \pm 3,47^{b}$ \\
\hline
\end{tabular}

* Letras diferentes na mesma linha indicam diferença significativa $(p<0,05)$ nas diferentes idades.

Quadro 2 Valores médios e desvios-padrão $(x \pm s)$ de proteínas séricas totais $(\mathrm{PT})$, proteínas plasmáticas totais (PPT), fibrinogênio (Fib), albumina (Alb), alfa1, alfa2, beta e gamaglobulinas, globulina total (Glob), relação albumina:globulina (A:G), imunoglobulina $\mathrm{G}(\mathrm{IgG})$ e atividade da gamaglutamiltransferase (GGT) em bezerros sadios da raça Limousin nos primeiros 120 dias de vida

\begin{tabular}{ccccccc}
\hline & 24 a $36 \mathrm{~h}$ & 15 dias & 30 dias & 60 dias & 90 dias & 120 dias \\
\hline PT $(\mathrm{g} / \mathrm{dL})$ & $6,32 \pm 0,98^{\mathrm{b}}$ & $6,34 \pm 0,85^{\mathrm{b}}$ & $6,29 \pm 1,03^{\mathrm{b}}$ & $6,80 \pm 1,09^{\mathrm{ab}}$ & $6,80 \pm 0,98^{\mathrm{ab}}$ & $7,26 \pm 0,88^{\mathrm{a}}$ \\
PPT $(\mathrm{g} / \mathrm{dL})$ & $8,37 \pm 0,84^{\mathrm{a}}$ & $7,58 \pm 0,51^{\mathrm{b}}$ & $7,24 \pm 0,38^{\mathrm{c}}$ & $7,24 \pm 0,40^{\mathrm{c}}$ & $7,71 \pm 0,50^{\mathrm{b}}$ & $8,10 \pm 0,44^{\mathrm{a}}$ \\
Fib $(\mathrm{mg} / \mathrm{dL})$ & $338 \pm 160^{\mathrm{b}}$ & $534 \pm 230^{\mathrm{a}}$ & $388 \pm 163^{\mathrm{b}}$ & $427 \pm 196^{\mathrm{ab}}$ & $434 \pm 179^{\mathrm{ab}}$ & $352 \pm 211^{\mathrm{b}}$ \\
Alb (g/dL) & $2,09 \pm 0,44^{\mathrm{d}}$ & $3,22 \pm 0,56^{\mathrm{c}}$ & $3,71 \pm 0,67^{\mathrm{b}}$ & $4,22 \pm 0,78^{\mathrm{a}}$ & $4,04 \pm 0,62^{\mathrm{ab}}$ & $4,07 \pm 0,61^{\mathrm{ab}}$ \\
Alfa $_{1}(\mathrm{~g} / \mathrm{dL})$ & $0,54 \pm 0,18^{\mathrm{a}}$ & $0,46 \pm 0,13^{\mathrm{bc}}$ & $0,39 \pm 0,09^{\mathrm{c}}$ & $0,46 \pm 0,119^{\mathrm{bc}}$ & $0,44 \pm 0,09^{\mathrm{bc}}$ & $0,47 \pm 0,08^{\mathrm{b}}$ \\
Alfa $_{2}(\mathrm{~g} / \mathrm{dL})$ & $0,36 \pm 0,09^{\mathrm{c}}$ & $0,45 \pm 0,11^{\mathrm{b}}$ & $0,47 \pm 0,10^{\mathrm{b}}$ & $0,53 \pm 0,11^{\mathrm{a}}$ & $0,49 \pm 0,08^{\mathrm{ab}}$ & $0,47 \pm 0,07^{\mathrm{b}}$ \\
Beta $(\mathrm{g} / \mathrm{dL})$ & $0,64 \pm 0,13^{\mathrm{b}}$ & $0,81 \pm 0,14^{\mathrm{a}}$ & $0,79 \pm 0,17^{\mathrm{a}}$ & $0,73 \pm 0,19^{\mathrm{a}}$ & $0,63 \pm 0,13^{\mathrm{b}}$ & $0,57 \pm 0,11^{\mathrm{b}}$ \\
Gama $(\mathrm{g} / \mathrm{dL})$ & $2,69 \pm 1,03^{\mathrm{a}}$ & $1,40 \pm 0,48^{\mathrm{c}}$ & $0,93 \pm 0,27^{\mathrm{de}}$ & $0,80 \pm 0,24^{\mathrm{e}}$ & $1,19 \pm 0,44^{\mathrm{cd}}$ & $1,69 \pm 0,46^{\mathrm{b}}$ \\
Glob (g/dL) & $4,23 \pm 1,06^{\mathrm{a}}$ & $3,12 \pm 0,57^{\mathrm{bc}}$ & $2,58 \pm 0,47^{\mathrm{d}}$ & $2,52 \pm 0,58^{\mathrm{d}}$ & $2,76 \pm 0,57^{\mathrm{c}}$ & $3,19 \pm 0,54^{\mathrm{b}}$ \\
A:G & $0,54 \pm 0,23^{\mathrm{e}}$ & $1,06 \pm 0,25^{\mathrm{d}}$ & $1,46 \pm 0,23^{\mathrm{b}}$ & $1,72 \pm 0,33^{\mathrm{a}}$ & $1,53 \pm 0,32^{\mathrm{b}}$ & $1,30 \pm 0,27^{\mathrm{c}}$ \\
IgG (g/dL) & $3,01 \pm 0,84^{\mathrm{b}}$ & $2,40 \pm 0,48^{\mathrm{d}}$ & $2,34 \pm 0,36^{\mathrm{d}}$ & $2,48 \pm 0,38^{\mathrm{d}}$ & $2,92 \pm 0,50^{\mathrm{c}}$ & $3,47 \pm 0,67^{\mathrm{a}}$ \\
GGT Ul/L & $1002.53 \pm 762,33^{\mathrm{a}}$ & $97,03 \pm 66,18^{\mathrm{b}}$ & $25,05 \pm 11,79^{\mathrm{c}}$ & $20,89 \pm 34,03^{\mathrm{c}}$ & $13,36 \pm 3,48^{\mathrm{c}}$ & $13,38 \pm 2,58^{\mathrm{c}}$
\end{tabular}

* Letras diferentes na mesma linha indicam diferença significativa $(p<0,05)$ nas diferentes idades.

Os níveis críticos de lgG, no soro sangüíneo dos bezerros, apontados como indicadores do sucesso incontestável da TIP variam de $1000 \mathrm{mg} / \mathrm{dL}$ (Radostits et al. 2002) a $1600 \mathrm{mg} / \mathrm{dL}$ (McGuire \& Adams 1982). Valores entre 500 e $1500 \mathrm{mg} / \mathrm{dL}$ (Selim et al. 1995) e de $600 \mathrm{a}$ $1600 \mathrm{mg} / \mathrm{dL}$ (McGuire \& Adams 1982) podem ser indicativos de FTIP parcial. Considerando-se os valores individuais obtidos, apenas dois dos bezerros estudados, ambos da raça Limousin, poderiam ser enquadrados na condição de FTIP parcial, exibindo valores séricos de gamaglobulinas de 800 e $850 \mathrm{mg} / \mathrm{dL}$ e de $\mathrm{IgG}$ de 1340 e $1480 \mathrm{mg} / \mathrm{dL}$. Os valores médios de gamaglobulinas e de IgG obtidos ao término do primeiro dia de vida foram, nas duas raças investigadas, muito superiores a esses apontados como críticos.

Durante o período experimental somente oito $(8,9 \%)$ dos 90 bezerros selecionados manifestaram doenças. Quadros diarréicos transitórios, de curta duração e não causadores de desequilíbrios evidentes foram observados em quatro bezerros da raça Limousin e em dois da raça Nelore, entre 15 e 30 dias de idade. O espessamento das estruturas umbilicais extracavitárias foi identificado em um bezerro Limousin aos 15 dias de vida. O processo não se agravou posteriormente. Um único bezerro da raça Limousin morreu aos 50 dias de idade portador de um provável quadro de infecção por hemoparasitas.

Dentre as idades avaliadas, a maior concentração de gamaglobulinas foi verificada com 24 a $36 \mathrm{~h}$ de vida (Fig.2), indicando o teor máximo após a absorção das imunoglobulinas colostrais. A opção por esse momento de colheita, e nunca antes de $24 \mathrm{~h}$ completas de idade, teve a finalidade de evitar a curva ascendente que antecede o pico de concentração sérica (Fagliari et al. 1996, Borges 1997, Feitosa et al. 2001b, Leal et al. 2003, Machado Neto et al. 2004). Decidiu-se não colher amostras antes da mamada do colostro devido à grande dificuldade operacional para a execução desse procedimento em bovinos manejados extensivamente, assim como à possibilidade de os bezerros perinatos manipulados sofrerem rejeição pelas mães. 


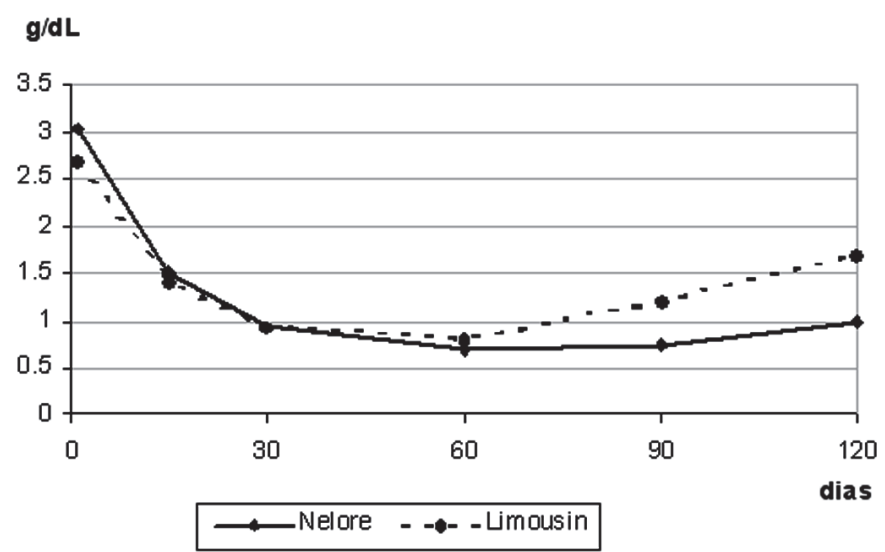

Fig.2. Curva da concentração de gamaglobulina sérica em bezerros sadios das raças Nelore e Limousin nos primeiros 120 dias de vida.

Segue-se ao valor máximo da concentração sérica uma redução contínua das imunoglobulinas circulantes conseqüente à degradação e à sua combinação com antígenos. A meia-vida plasmática da IgG é de 21 dias no bezerro (Logan et al. 1972). A curva obtida para as gamaglobulinas (Fig.2), coerente com a variação da IgG (Quadros 1 e 2), exibe o formato clássico representativo desse processo fisiológico (Feitosa et al. 2001b, Amorim 2002, Leal et al. 2003, Machado Neto et al. 2004). Os valores mínimos ocorreram ao redor dos 60 dias de idade, o que está de acordo com os resultados de Amorim (2002) em bezerros Nelore. Nas raças destinadas à produção de leite, por outro lado, a concentração mínima de anticorpos no sangue ocorre ao redor dos 30 dias de idade (Ribeiro et al. 1983, Borges 1997, Moraes et al. 1997, Costa 2000, Feitosa et al. 2001b, Pauletti et al. 2002). Essa discrepância pode ser devida ao fator racial, bem como, aos sistemas de criação distintos dos animais. Os bezerros leiteiros manejados intensivamente estão normalmente mais sujeitos ao contato freqüente e mais precoce com agentes infecciosos, o que pode causar consumo dos anticorpos circulantes. Os bezerros de corte manejados extensivamente são, por sua vez, submetidos a desafios naturais de menor magnitude com esses agentes. Contrariando os resultados presentes, Machado Neto et al. (2004) também observaram valores mínimos de IgG em torno dos 30 dias de vida em bezerros Nelore e Canchim, os quais, no entanto, foram separados de sua mães ao nascimento e mamaram colostro de forma artificial.

Até os 60 dias de idade os valores médios de gamaglobulinas circulantes não foram diferentes entre taurinos e zebuínos (Fig.2). A elevação que se estabeleceu no terceiro e quarto meses de vida (Quadros 1 e 2 ) foi distinta nas duas raças, demonstrando que a produção ativa de anticorpos foi mais precoce nos bezerros da raça Limousin. Esse comportamento é coerente com os comprovados em taurinos de raças leiteiras (Ribeiro et al. 1983, Borges 1997, Costa 2000, Feitosa et al. 2001b, Pauletti et al. 2002). Machado Neto et al. (2004) obtiveram resulta- dos semelhantes demonstrando que a curva ascendente de IgG no soro sangüíneo também foi mais precoce em bezerros Canchim comparados aos Nelore. Amorim (2002) observou igualmente uma elevação muito lenta da concentração de gamaglobulinas em bezerros da raça Nelore até os 150 dias de vida. $O$ conjunto de evidências sugere que a síntese ativa de imunoglobulinas pelo sistema imunológico cada vez mais competente pode ser um processo mais tardio nos zebuínos do que nos taurinos. Vale a ressalva de que durante todo o período experimental nenhum bezerro participante do estudo foi submetido a qualquer tipo de estimulação antigênica artificial (vacinação), fato que poderia justificar a diferença observada.

Admite-se comumente que o bezerro esteja mais suscetível a contrair infecções nessa faixa etária crítica marcada pelo intervalo de tempo em que se mantêm as menores concentrações séricas de gamaglobulinas, período entre o término do processo de degradação das imunoglobulinas passivamente transferidas e a produção ativa pelo sistema imunológico competente (Radostits et al. 2002). Nesse particular, os bezerros Nelore poderiam ser considerados mais sujeitos a sofrerem doenças do que os da raça Limousin, pois o período crítico mencionado se prolongou do segundo ao quarto mês de vida, enquanto que nos taurinos restringiu-se ao segundo mês (Fig.2). Os quadros diarréicos observados nos poucos animais que adoeceram ocorreram, contudo, no primeiro mês de vida. Deve-se considerar primeiro, que a imunidade humoral não é a única responsável pela defesa do organismo (Tizard 2002). Segundo, o desafio imposto em condições de manejo extensivo é, de forma geral, menor. Terceiro, os manejos adotados nas propriedades eram adequados. E, por último, mesmo no período crítico mencionado, a concentração média de gamaglobulinas não alcançou valores tão reduzidos nos bezerros da raça Nelore (variando próximo a $700 \mathrm{mg} / \mathrm{dL}$ ). Em suma, os taurinos podem desenvolver a capacidade de imunidade humoral ativa mais precocemente que os zebuínos. Mas isso não significa, necessariamente, que os zebuínos estejam mais sujeitos à infecção nesses primeiros meses de vida.

Uma alteração na relação albumina:globulina (A:G) geralmente é o primeiro sinal de alteração no perfil protéico normal. As maiores variações fisiológicas ocorrem ao longo do primeiro mês de vida e são fruto da flutuação dos dois tipos de proteína (Leal et al. 2003). Em ambas as raças estudadas observou-se o mesmo comportamento. A concentração de albumina foi menor ao nascimento e se elevou até os 60 dias de vida (Quadros 1 e 2). As globulinas, elevadas após a absorção de IgG maternas, reduziram-se no mesmo período. A inversão nas concentrações de albumina e de globulina ocorrida em torno dos 15 dias de vida levou ao aumento da relação A:G. Esta relação tende a diminuir após o início da produção endógena de gamaglobulinas. As frações alfa ${ }_{1}$, alfa 2 betaglobulinas apresentaram variações não muito expressivas ao longo do tempo e parecidas nas duas raças. 
A gamaglutamiltransferase (GGT) é uma enzima hepática e está presente em concentração elevada no colostro dos bovinos, sendo absorvida em grande quantidade pelas células intestinais dos bezerros recém-nascidos (Braun et al. 1982, Fagliari et al. 1996, Zanker et al. 2001). Dessa forma, pode-se considerar a atividade sérica da GGT como um indicador indireto da capacidade do neonato absorver imunoglobulinas (Feitosa et al. 2001a). Em ambas as raças estudadas, a enzima apresentou valor máximo de atividade no soro das 24 às $36 \mathrm{~h}$ de vida, decrescendo abruptamente até atingir os valores fisiológicos aos 60 dias de idade (Quadros 1 e 2). Tais evidências são compatíveis com as descritas pelos autores mencionados e refletem uma variação fisiológica própria do período neonatal.

Considerando os resultados obtidos ao término do primeiro dia de vida e assumindo os valores de gamaglobulinas como padrão para comparação, observaram-se correlações elevadas entre os mesmos e os de $\lg G(r=0,859)$, PPT $(r=0,807)$, PT $(r=0,811)$ e Glob $(r=0,966)$, reforçando evidências anteriores de que essas variáveis são indicadores da TIP nos bezerros (Naylor \& Kronfeld 1977, Pfeiffer et al. 1977, Moraes et al. 1997, Feitosa et al. 2001a, Machado Neto et al. 2004). Apesar de significativa, a correlação entre a atividade sérica da GGT e a gamaglobulina foi fraca ( $r=0.399$ ), o que contrasta com outras observações (Fagliari et al. 1996, Feitosa et al. 2001a). Isto pode ser devido à grande variabilidade observada nos valores da atividade sérica da enzima e ao fato de que, a partir das 24 horas de vida, o declínio da atividade da GGT antecede 0 da concentração das gamaglobulinas (Borges 1997). A correlação será tão mais forte quanto mais próximo das 24 horas de vida as amostras forem colhidas. Nesse estudo, por motivo de dificuldades operacionais e porque muitos partos ocorrem à noite, um grande número de colheitas de sangue aconteceu após os bezerros terem completado 30 horas de idade.

Pode-se concluir que a transferência de imunidade passiva foi bem sucedida nos bezerros de ambas as raças e o número de parições das mães não interferiu no processo. As variações das proteínas séricas obedeceram a um padrão de comportamento fisiológico ao longo dos quatro primeiros meses de vida e a produção ativa de imunoglobulinas foi mais precoce nos bezerros da raça Limousin e mais lenta nos da raça Nelore, sem provocar qualquer impacto sobre a saúde dos mesmos. Os valores de IgG estimados pelo método da turvação pelo sulfato de zinco e das proteínas séricas e plasmáticas foram bons indicadores da transferência de imunidade passiva nos bezerros entre 24 e 36 horas de vida.

Agradecimentos.- Aos acadêmicos de Medicina Veterinária da UEL, bolsistas de Iniciação Científica, Romerson Dognani e Evandro Doine Vettorato, pelo auxílio na execução dos procedimentos experimentais de colheita de material e de determinações laboratoriais. Ao engenheiro agrônomo Dr. José Renato Silva Gonçalves, responsável técnico da Fazenda Figueira e Estação Experimental Agrozootécnica da FEALQ.

\section{REFERÊNCIAS}

Amorim R.M. 2002. Valores séricos e hepáticos de elementos minerais, atividade sérica da ceruloplasmina, hemograma, proteinograma e metabolismo oxidativo dos neutrófilos em bezerros da raça Nelore, nascidos de mães com nutrição adequada ou inadequada em cobre e zinco. Tese de Doutorado em Clínica Veterinária, Faculdade de Medicina Veterinária e Zootecnia, Universidade Estadual Paulista, Botucatu. 158p.

Besser T.E. \& Gay C.C. 1994. The importance of colostrum to the health of the neonatal calf. Vet. Clin. Food Anim. 10(1):107-117.

Bessi R., Pauletti P., D’Arce R.C. \& Machado Neto R. 2002. Absorção de anticorpos do colostro em bezerros I. Estudo no intestino delgado proximal. Revta Bras. Zootec. 31(6):2314-2324.

Borges A.S. 1997. Avaliação da eficácia da administração de plasma, por via intravenosa, como tratamento da falência de transferência de imunidade passiva em bezerros da raça Holandesa. Dissertação de Mestrado em Clínica Veterinária, Faculdade de Medicina Veterinária e Zootecnia, USP, São Paulo. 141p.

Bradley J.A., Niilo L. \& Dorward W.J. 1978. Some observations on serum gammaglobulin concentrations in suckled beef calves. Can. Vet. J. 20(9):227-232.

Braun J.P., Tainturier D., Laugier C., Bénard P., Thouvenot J.P. \& Rico A.G. 1982. Early variations of blood plasma gamma-glutamyl transferase in newborn calves: A test of colostrum intake. J. Dairy Sci. 65(11):2178-2181.

Costa J.N. 2000. Leucograma, metabolismo oxidativo dos neutrófilos, proteinograma e imunoglobulinas de bovinos da raça holandesa (Bos taurus). Influência do desenvolvimento etário e da suplementação com vitamina $\mathrm{E}$ (acetato de DL-alfa-tocoferol). Tese de Doutorado em Clínica Veterinária, Faculdade de Medicina Veterinária e Zootecnia, Universidade Estadual Paulista, Botucatu. 209p.

Curi P.R. 1998. Metodologia e Análise da Pesquisa em Ciências Biológicas. $2^{\underline{a}}$ ed. Gráfica e Editora Tipomic, Botucatu. 263p.

Devery-Pocius J.E. \& Larson B.L. 1983. Age and previous lactation as factors in the amount of bovine colostral immunoglobulin. J. Dairy Sci. 66(2):221-226.

Fagliari J.J., Oliveira E.C., Pegorer M.F., Ferrante Júnior L.C. \& Campos Filho E. 1996. Relação entre o nível sérico de gamaglobulinas e as atividades de gama glutamiltransferase, fosfatase alcalina e aspartato aminotransferase de bezerros recém-nascidos. Arq. Bras. Med. Vet. Zootec. 48(2):105-112.

Fagliari J.J., Passipieri M., Curi P.R., Ferreira Neto J.M. \& Lucas A. 1988. Valores padrões das proteínas séricas de bovinos da raça Guzerá II. Proteinograma sérico de bezerros recém-nascidos. Ars Vet. 4(2):225-232.

Fagliari J.J., Santana A.E., Lucas F.A., Campos Filho E. \& Curi P.R. 1998. Constituintes sanguíneos de bovinos recém-nascidos das raças Nelore (Bos indicus) e Holandesa (Bos taurus) e de bubalinos (Bubalus bubalis) da raça Murrah. Arq. Bras. Med. Vet. Zootec. 50(3):253-262.

Feitosa F.L.F., Birgel E.H., Mendes L.C.M. \& Perri S.H.V. 1999. Relação entre a concentração de imunoglobulinas colostrais e a transferência de imunidade passiva para bezerros da raça Holandesa após ingestão voluntária do colostro. Ciênc. Vet. Tróp. 2(3):160-168.

Feitosa F.L.F., Birgel E.H., Mirandola R.M.S. \& Perri S.H.V. 2001a. Diagnóstico de falha de transferência de imunidade passiva em bezerros através da determinação de proteína total e de suas frações eletroforéticas, imunoglobulinas $\mathrm{G}$ e $\mathrm{M}$ e da atividade da gama glutamiltransferase no soro sangüíneo. Ciência Rural 31(2):251-255.

Feitosa F.L.F., Birgel E.H., Mirandola R.M.S. \& Perri S.H.V. 2001b. Proteinograma sérico de bezerros holandeses do nascimento até um ano de vida. Revta Bras. Ciênc. Vet. 8(2):105-108.

Filteau V., Bouchard E., Fecteau G., Dutil L. \& DuTremblay D. 2003. Health status and risk factors associated with failure of passive transfer 
of immunity in newborn beef calves in Quebec. Can. Vet. J. 44(11):907913.

Gornal A.G., Bardawill C.J. \& David M.M. 1949. Determination of serum proteins by means of the biuret reaction. J. Biol. Chem. 177(1):751766.

Guy M.A., McFadden T.B., Cockrell D.C. \& Besser T.E. 1994. Regulation of colostrum formation in beef and dairy cows. J. Dairy Sci. 77(10):30023007.

Kremers B., Briere R. \& Batsakis J.G. 1967. Reflectance densitometry of cellulose acetate protein eletrophoresis. Am. J. Med. Technol. 33(1):28-34.

Leal M.L.R., Benesi F.J., Lisbôa J.A.N., Coelho C.S. \& Mirandola R.M.S. 2003. Proteinograma sérico de bezerras sadias, da raça holandesa, no primeiro mês pós-nascimento. Braz. J. Vet. Res. Anim. Sci. 40(2):138-145.

Logan E.F., Penhale W.J. \& Jones R.A. 1972. Changes in the serum immunoglobulins of colostrum fed calves during the first twelve weeks postpartum. Res. Vet. Sci. 14:394-397.

Machado Neto R. \& D'Arce R.D. 1979. Gamaglobulinas séricas de bezerros recém-nascidos da raça Nelore. Revta Soc. Bras. Zootec. 8(1):33-42.

Machado Neto R., Packer I.U., Bonilha L.M., Figueiredo L.A., Razzok A.G. \& Cândido J.G. 1997. Concentração de IgG sérica em bezerros das raças Nelore, Guzerá, Gir e Caracu. 1. Estatísticas descritivas e causas de variação. Revta Bras. Zootec. 26(5):914-919.

Machado Neto R., Packer I.U., Prado G.V.B., Bessi R. \& Pauletti P. 2004. Colostral immunoglobulins absorption in Canchim and Nelore calves. Revta Bras. Zootec. 33(6):1544-1547.

McGuire T.C. \& Adams D.S. 1982. Failure of colostral immunoglobulin transfer to calves: prevalence and diagnosis. Compend. Contin. Educ. Vet. 4(1):S35-S40.

Moraes M.P., Weiblen R., Silva A.M. \& Tobias F.L. 1997. Evolução da imunidade passiva em fêmeas bovinas da raça Holandesa. Ciência Rural 27(3):435-440.

Muller L.D. \& Ellinger D.K. 1981. Colostral immunoglobulin concentration among breeds of dairy cattle. J. Dairy Sci. 64(8):1727-1730.

Naylor J.M. \& Kronfeld D.S. 1977. Refractometry as a measure of the immunoglobulin status of the newborn dairy calf: comparison with the zinc sulphate turbidity test and single radial immunodiffusion. Am. J. Vet. Res. 38(9):1331-1334.

Norman L.M. \& Hohenboken W.D. 1981. Genetic differences in concentrations of immunoglobulins $\mathrm{G} 1$ and $\mathrm{M}$ in serum and colostrum of cows and in serum of neonatal calves. J. Anim. Sci. 53(6):14651472.

Oyeniyi O.O. \& Hunter A.G. 1978. Colostral constituents including immunoglobulins in the first three milking postpartum. J. Dairy Sci. 61(1):44-48.
Pauletti P., Machado Neto R., Packer I.U. \& Bessi R. 2002. Avaliação de níveis séricos de imunoglobulina, proteína e o desempenho de bezerras da raça holandesa. Pesq. Agropec. Bras. 37(1):89-94.

Perino L.J., Wittum T.E. \& Ross G.S. 1995. Effects of various risk factors on plasma protein and serum immunoglobulin concentrations of calves at postpartum hours 10 and 24. Am. J. Vet. Res. 56(9):1144-1148.

Petrie L., Acres S.D. \& McCartney D.H. 1984. The yield of colostrum and colostral gamma globulins in beef cows and the absorption of colostral gamma globulins by beef calves. Can. Vet. J. 25(7):273279.

Pfeiffer N.E., McGuire T.C., Bendel R.B. \& Weikel J.M. 1977. Quantitation of bovine immunoglobulins: comparison of single radial immunodiffusion, zinc sulfate turbidity, serum electrophoresis, and refratometer methods. Am. J. Vet. Res. 38(5):693-698.

Pritchett L.C., Gay C.C., Besser T.E. \& Hancock D.D. 1991. Management and production factors influencing immunoglobulin $G_{1}$ concentration in colostrum from Holstein cows. J. Dairy Sci. 74(7):2336-2341.

Radostits O.M. \& Acres S.D. 1980. The prevention and control of epidemics of acute undifferentiated diarrhea in beef calves in western Canada. Can. Vet. J. 21(9):243-249.

Radostits O.M., Gay C.C., Blood D.C. \& Hinchcliff K.W. 2002. Doenças do recém-nascido, p.102-136. In: (ed.), Clínica Veterinária: Um tratado de doenças dos bovinos, ovinos, suínos, caprinos e eqüinos. 9a ed. Guanabara Koogan, Rio de Janeiro.

Ribeiro M.F.B., Salcedo J.H.P., Belém P.A.D. \& Faria J.E. 1983. Hipogamaglobulinemia em bezerros. Arq. Bras. Med. Vet. Zootec. 35(4):537-546.

Schalm O.W., Jain N.C. \& Carroll E.J. 1975. Veterinary Hematology. 3rd ed. Lea and Febiger, Philadelphia. 1220p.

Selim S.A., Smith B.P., Cullor J.S., Blanchard P., Farver T.B., Hoffman R., Dilling G., Roden L. \& Wilgenburg B. 1995. Serum immunoglobulins in calves: their effects and two easy, reliable means of measurement. Vet. Med. 90(4):387-404.

Szasz G. 1969. A kinetic photometric method for serum gamma-glutamyl transpeptidase Clin. Chem. 15:124-36.

Tizard I.R. 2002. Imunidade no feto e no recém-nascido, p.233-246. In: Paulo. (ed.), Imunologia Veterinária: uma introdução. $6^{a}$ ed. Roca, São

Wittum T.E. \& Perino L.J. 1995. Passive immune status at postpartum hour 24 and long-term health and performance of calves. Am. J. Vet. Res. 56(9):1149-1154.

Zanker I.A., Hammon H.M. \& Blum J.W. 2001. Activities of gglutamyltransferase, alkaline phosphatase and aspartate-aminotransferase in colostrum, milk and blood plasma of calves fed first colostrum at 0-2, 6-7, 12-13 and 24-25 h after birth. J. Vet. Med. A, Physiol. Pathol. Clin. Med. 48(3):179-185. 